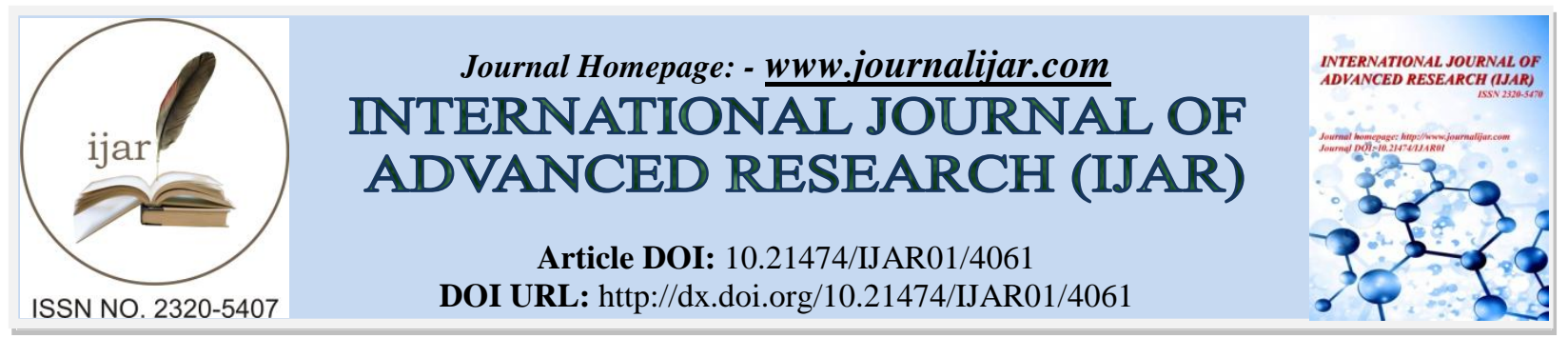

RESEARCH ARTICLE

\title{
STRATEGIES FOR EFFECTIVE RURAL DEVELOPMENT IN INDIA: AN OVER VIEW.
}

\section{Dr. Sangappa V. Mamanshetty.}

Assitant Professor \& HOD, Dept.of Economics, Government First Grade College, Chincholi-585307.Tq. Chincholi.Dist. Kalabuargi, Karnataka-State (India)

\section{Manuscript Info}

Manuscript History

Received: 26 February 2017

Final Accepted: 30 March 2017

Published: April 2017

Key words:-

Rural development, Agriculture

products, rural development strategies,

Indian economy.

\begin{abstract}
The people lives in rural areas are majorly depends on agriculture. The rural agricultural production \& consumption process plays a predominant role in developing the Indian economy. The major objective of rural development is to increase farm productivity, for achieving rapid economic transformation, increasing profits to farmers and to increase the household outputs of selected agricultural products. The paper majorly focused on the various rural development management of land, labour and natural resources to the effective harvesting, pre processing methods and effective marketing strategies to be followed. Although policy makers and the development community have widely used the phrase "rural development", what constitutes rural development seems to have changed significantly overtimes. The concept of rural development has changed significantly during the last three decades. Until the 1970s, rural development was synonymous with agricultural development and hence focused on increasing agricultural production. This focus seems to have been driven primarily by the interest of industrialization to extract surpluses from the agriculture sector to reinforce industrialization.
\end{abstract}

Copy Right, IJAR, 2017,. All rights reserved.

\section{Introduction:-}

The rural agricultural production \& consumption process plays a predominant role in developing the Indian economy. Agriculture and agro processing account for 30-60\% of GDP in developing countries. 63 percent of population lives in rural areas only. With rapid urbanization rural people depends mostly on agriculture. India started producing about 700 million tonnes of biological materials per year including food grains, fruits, oilseeds, vegetables, milk, eggs, tea, coffee, fibber crops, forest produce and so on. Because of its socio economic impact specifically on employment and income generation, Agro processing is now regarded as the sunrise sector of the Indian economy. The common agro processing industries includes paper making units, hand pounding units for rice, bullock operated sugarcane crushers, water power driven flour mills, bullock driven oil grannies, spinning wheels and handloom units for weaving etc. The rural areas are consuming a large number of industrial and urban manufactured products.

\section{Meaning and Concept:-}

Although policy makers and the development community have widely used the phrase "rural development", what constitutes rural development seems to have changed significantly overtimes. The concept of rural development has 
changed significantly during the last three decades. Until the 1970s, rural development was synonymous with agricultural development and hence focused on increasing agricultural production. This focus seems to have been driven primarily by the interest of industrialization to extract surpluses from the agriculture sector to reinforce industrialization.

The establishment of the Millennium Development Goals has significantly reinforced the concerns about nonincome poverty. With the parading shifts in economic development from "growth" to broadly defined "development", the concept of rural development has begun to be used in a broader sense. In more recent years increased concerns on the environmental' aspects of economic growth have also influenced the changes. Today's concept of rural development is fundamentally different from that used about three or four decades ago.

The concept now encompasses "concerns that go well beyond improvements in growth, income and output. The concern include an assessment of changes in the quality of life, broadly defined to include improvement in health and nutrition, education, environmentally safe living conditions and reduction in gender and Income inequalities.

Today, there seems to be a universal consensus that the ultimate objective of rural development is to improve the quality of life of rural people. This makes it essential to go beyond the income-related factors such as prices, production, and productivity to a range of non- income factors that influence quality of life and hence inclusiveness of rural development."

Inclusive rural development is more specific concept than the concept of rural development. In broader terms, inclusive rural development is about improving the quality of life of all members of rural society. More specifically, inclusive rural development covers three different but interrelated dimensions.

1. Economic dimension

2. Social dimension

3. Political dimension

Economic dimension encompasses providing both capacity and opportunities for the poor and low-income households in particular III benefit from the economic growth. Social dimension supports social development of poor and low- Income households, promotes gender equality and women's empowerment and provides social safety nets for vulnerable groups.

Political dimension improves the opportunities for the poor and low Income people in rural areas to effectively and equally participate III the political processes at the village level.

The notion of rural development has been conceived in diverse ways by researchers, ranging from thinking of it as a set of goals and programmes to a well-knit strategy, approach or even an ideology. There is a widely shared view that its essence should be poverty alleviation and distributive Justice oriented economic transformation.

\section{Objectives of Rural Development:-}

1. To improve the living standards by providing food, shelter, clothing, employment and education.

2. To Increase productivity in rural areas and reduce poverty.

3. To involve people in planning and development through their participation in decision making and through centralization of administration.

4. To ensure distributive Justice and equalization of opportunities in the society.

Following are the primary objectives of rural Development:Strategies in Rural Development:-

A strategy consists of an ordering of various policy parameters to attain the desired goals. Different strategies emphasize and give importance to different mixes of agrarian relations, techniques of production and state policies in order to achieve the goals of rural development. To illustrate some of the relevant issues, there air various types of rural development strategies. 
Followings are various types of rural development strategies giving central importance to agrarian relations for purpose of classification:-

1. A strategy based on collectivization of resources.

2. A strategy based on regulated capitalist perspective.

3. A strategy based on peasant agrarian perspective.

4. A strategy based on Laissez-Faire or un-regulated free market capitalist perspective.

These strategies do not constitute an exhaustive list and are simply illustrative

Strategy based on Collectivization of Resources:-

Collectivization of rural assets (particularly land) is given almost importance in the first strategy. Private ownership of land is abolished so that not only inequalities in the ownership of land are eliminated but also land use can be made more productive.

The latter is achieved because small plots of land can be consolidated so that large scale cultivation also raises productivity by creating possibilities for the use of modem technology in the shape of tractors, harvesters etc. This strategy with fairly good success was followed in the Soviet Union, China and the East-European countries.

These countries were able to make sharp Increases in production soon after they initiated this strategy. However, for a variety of reasons which are too complex to be recalled here, the erstwhile socialist regimes have collapsed or changed course dramatically and this strategy is not in operation anywhere currently.

\section{Strategy based on Regulated Capitalist Perspective:-}

This strategy envisions a co-existence of a capitalist sector and a peasant sector that gets same support and protection from the state. Any Large-scale redistribution of land or reconfiguration of land relations are ruled out. It is hoped that the objective of rapid growth would be taken care of by the capitalist sector while the peasant sector would address the problem of unemployment till the time the non-agricultural sectors start growing at a rapid pace.

It has been pointed out that without meaningful land reforms, I Ills strategy can only have limited success, rural inequalities are ignored in this strategy. Rural elites on the one hand exercise control and prevent changes that will bring about a change in the unequal distribution of assets (land) and on the other comer a large part of whatever resources are pumped in from "outside" to better the lives of the poor. An example of this is provided by the way banking co-operatives have operated in India.

A great portion of rural credit disbursed through co-operative Institutions has gone into the hands of those who are better off and have the capacity to mobilize their own resources. Thus, it is pointed out that this strategy avoids taking hard decisions to make a break-through in rural development that can create conditions for the rapid development in rural areas

\section{Strategy based on Peasant Agrarian Perspective:-}

The strategy based on the peasant agrarian perspective argues for thorough going redistribution of land and overhaul of land relations. It envisages strong support for small peasant units, which are supposed to take care of the twinobjectives of growth and employment.

An extensive network of co-operative Institutions, marketing facilities etc. is accorded critical importance in this strategy. Both in the second and the third strategies, it is envisaged that the state will play important roles in promoting and strengthening the non-agricultural economic activities in the rural areas, so as to ease the pressure of surplus labour on agriculture and to facilitate the creation of decent livelihood options elsewhere in the long run.

It is expected to perform a whole range of important functions. Furthermore, it is assumed that the problem of adequate infra structure in rural areas will be addressed by the state and also the investments in social sectors such as education, health etc.

Strategy based on Unregulated Capitalist Perspective:-

Such a strategy presumes that rich landowners will play the vanguard role in rapid increase in agricultural output, by taking advantage of the economies of scale and gradually the small cultivation units will disappear. It is suggested 
that the state should not intervene in the expansion of the capitalist sector and there should be no ceiling on ownership.

Unfettered expansion of this sector is supposed to provide a dynamism that will over, all rural economy and the benefits from it, through employment and increasing incomes, are supposed to percolate even to the lowest strata.

The Issues of inequality and distributive Justice are considered non-issues in such a strategy, to the extent the state has a role, it is with respect to infrastructure, but there too it is not viewed as the major actor necessarily.

\section{The core concerns of a rural development strategy may be listed here as follows: -}

1. Agricultural research, extension rural education and training programmes for farmers form a part of institution building activities.

2. Infrastructure building activity related to the growth of irrigation, transport, communications and health facilities.

3. Programmes to improve marketing facilities for the distribution of agricultural inputs and implements.

4. Policies related to land tenure, agricultural output, prices and taxation of agricultural incomes.

Based on the experience of market economies as regards to Hip approach towards distribution of land, types of strategies for fostering the growth of the agricultural sector can also be classified as "uni-modal" and "bi-modal" strategies.

\section{Uni-modal Strategy:-}

A uni-modal strategy is one in which land holdings arc equitably distributed. This strategy was followed with tremendous success in the case of Japan, Taiwan and Korea. It seeks to promote rural development through the use of thorough going reforms in the agricultural sector.

Thus, because of the land reforms and the consequent even distribution of rural assets, resources meant for the agricultural sector are also spread evenly.

This type of agricultural strategy creates a situation that enables rapid growth of agricultural production with equitable distribution of incomes. This in turn not only results in rapid rural development but also provides an important basis for overall economic development.

The bi-modal strategy:-

The bi-modal strategy for the growth of the agricultural sector attempts to increase agricultural production without making attempts to drastically change the skewed distribution of incomes and assets in rural areas. Many countries in Latin America are examples of this type of strategy. In this type of strategy, there is no attempt to bring about land reforms.

A large number of small farms co-exist with a small number of large size holdings. The idea is to concentrate modern technology and inputs to the latter and thereby achieve agricultural growth. Such a growth pattern clearly ignores a whole range of developmental concerns and is also unable to provide strong foundation for overall economic development. 


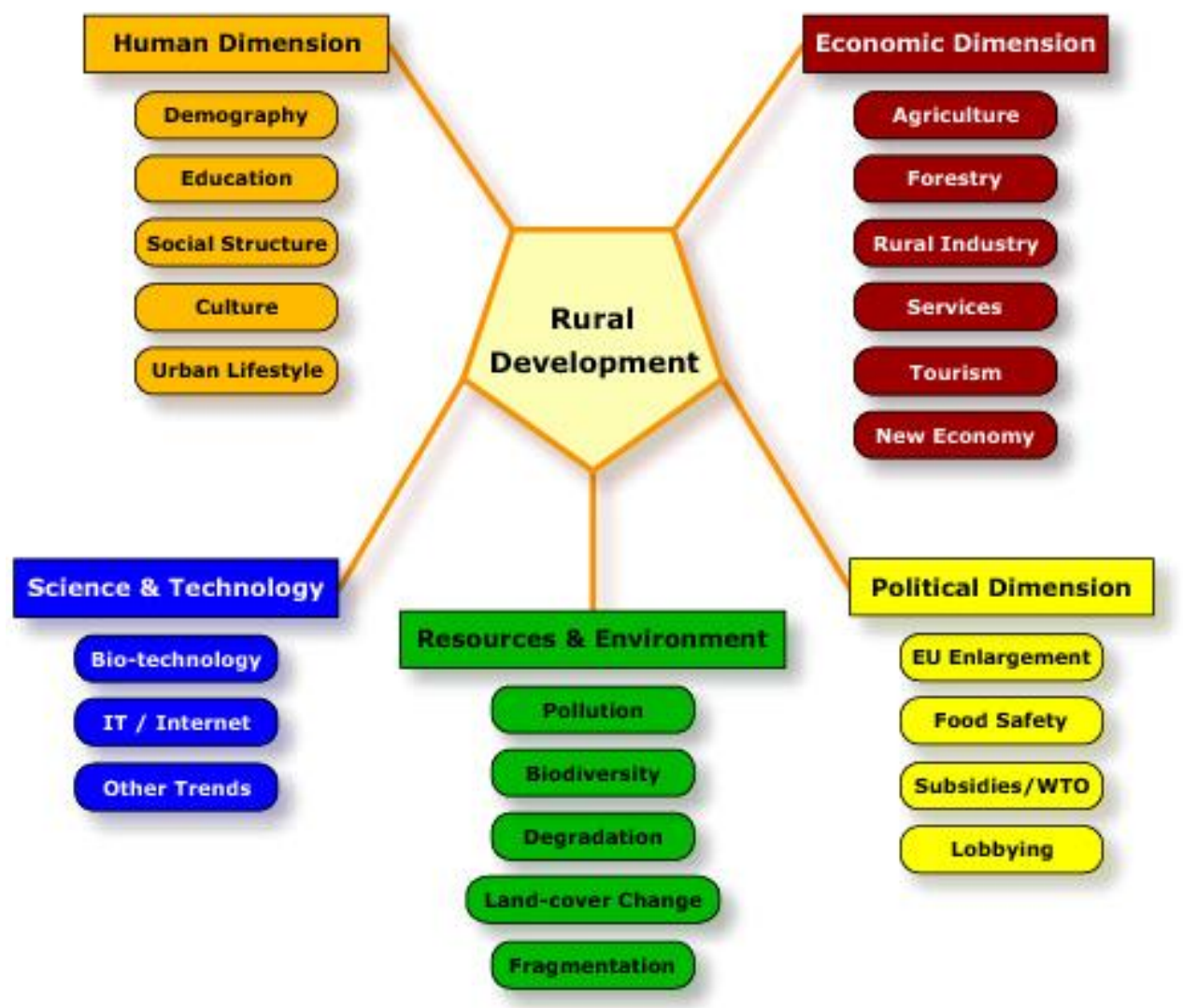

Figure.1:- Rural development. Source: Royal Commission Canada, 2003.

The major wings for the rural development are

1. Economic dimension

2. Human dimension

3. Science \& Technology

4. Resources and Environment

5. Political dimension.

\section{Need For Rural Development:-}

1. To raises the quality of life \& environment in rural areas.

2. To reduce urbanization

3. For the improvement of Indian economy

4. For the proper management of natural resources like land, water for agricultural production

5. To produce variety of food products through agriculture.

6. To improve profits for farmers.

\section{The implementation of rural Development:-}

The implementation of Rural development strategies will use \& develop existing institutional, management and funding mechanisms to focus the expenditure of government in the three spheres to more effectively and efficiently respond to needs and opportunities. So there is a great need to develop the rural areas for the improvement of Indian economy.

The objectives of the RDS are to increase farm productivity, for achieving rapid economic transformation, to increase household outputs of the selected agricultural products, and to promote value addition and ensure a stable market for these agricultural products. 
The effective rural development strategies to be followed are

1. Provision of support to the farmers Groups, and Associations in order to build their capacity and supporting farmer unions.

2. By adopting localized way of distributing agricultural products.

3. Water management for agricultural production by the Usage of sprinklers and drips.

4. Use of private companies for processing \& marketing.

5. By proper communication \& quality maintenance.

6. Enhancing Rural Micro finance services \& provision of subsidies for crops.

7. Strategy for provision of technology inputs to the farmers.

8. Liberalization of Markets and Price Structures.

9. All weather roads to rural habitations.

10. Better economic utilization of agricultural residues, byproducts \& Recycling of wastes by the establishment of separate plants at the village levels by the support of government.

11. Enhancement of linkage to farmer groups with processors and buyers for increasing the profits to the farmers.

12. Pests and disease control with the usage of improved seeds, Bio Fertilizers, Herbicides, and Bio Pesticides.

13. Usage of advanced equipment and machinery that constitutes the technology for the plantation and harvesting of the crops that leads to decrease the labor cost.

14. Agricultural Productivity Enhancement.

15. Research \& Development for agro processing technologies.

16. Provision of Support to agricultural related industries.

17. Establishment of farmer care centres.

18. Analysis of complete Agricultural trade statistics includes Tree crops, Consumption data, Diseases and disease control data, Statistics on agricultural products processing \& marketing, Fisheries statistics etc.

19. Increasing the organic farming.

Because of high utilization of pesticides and fertilizers by the farmers, scientists are advising the organic products. The agricultural products, that produced through organic farming termed as organic products. In the world market these organic products having high demand day to date. So, there is a great need to follow the organic farming by the Indian farmers and produce the organic foods and export to other countries for the propitiation. Worldwide the organic farming land increased $11 \%$ - 40\% from 1990 to 2010.

Shown in graph.1. 


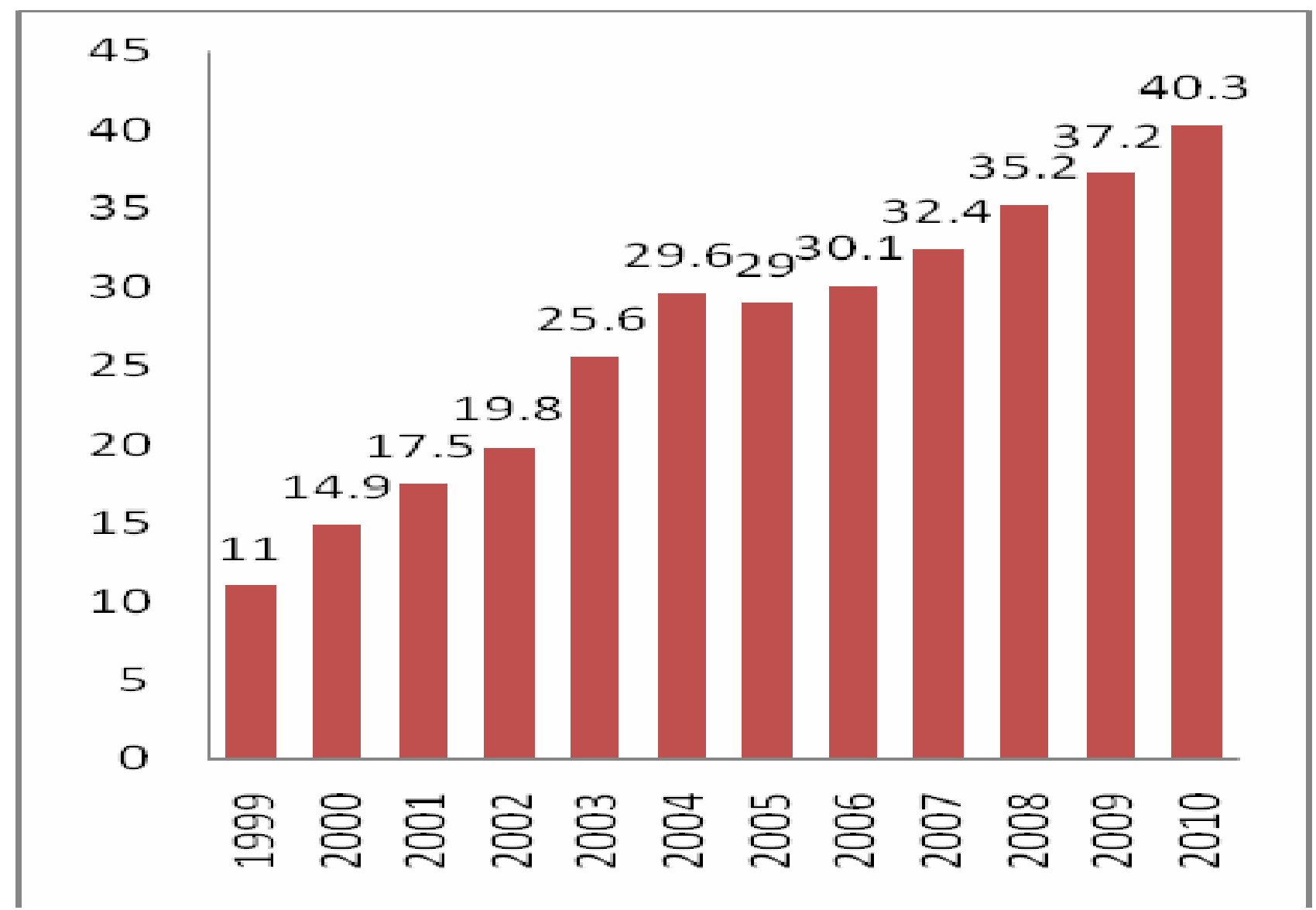

Graph-1:- Deevelopment of world organic agricultural land (1999 - 2010), Source: S-CEL 1999 - 2010

20. By conducting and organizing the camps / programs at the rural areas regarding development.

21. Establishment of separate teams for the rural development by the central government with special packages.

22. Maintenance of CLEAN \& GREEN at the villages.

23. By providing transport facilities to the rural areas.

24. Building of interactions with the agricultural experts for gaining more profits.

These are the different rural development strategies.

\section{Rural Marketing:-}

Rural marketing basically deals with delivering manufactured or processed inputs or services to rural producers. Rural Marketing would also be different they include input manufacturers, dealers, farmers, government agencies and traders. Thus, to promote their brands, they are exploiting social and cultural values. Increasing specialization in the farming sector has marketers to this strategy.

\section{Challenges For Rural Developmen:-t}

1. Developing rural areas is long time consuming process.

2. There is no doubt that, Most of the rural people depend on agriculture \& that is a risky business.

3. Sustainable economic growth and diversification;

4. Government funding and institutional development

5. Agricultural employment has started to decline and where replacement employment is required.

6. Lack of appropriate technology \& beneficiary participation.

\section{Conclusion:-}

More than $60 \%$ of the Indian population lives in rural areas and most of the rural people depend on agriculture and agricultural related industries. So there is a great need to follow the effective rural development strategies for improving the quality of life in rural areas, self employment to rural people and raising profits to the farmers to improve the Indian economy. 


\section{References:-}

1. B. Raymond, Regional and Rural Development Strategies in Canada, The Search For Solutions Royal Commission on Renewing and Strengthening Our Place in Canada, 2003.

2. C. Dankers, and P. Liu, FAO: Environmental and social standards, certification and labelling for cash crops, Commodities and Trade Technical Paper No. 2. Rome, 2003.

3. E. Wynen, Impact of organic guarantee systems on production and trade in organic products. fao-ifoam-unctad International Task Force on Harmonization and equivalence in organic agriculture, the Third Meeting, Rome 17 - 19, 2004.

4. G. V. Fox, G. Adamowicz, Debailleul and P. Thomassin, Agriculture and the Environment: Economic Dimensions of Sustainable Agriculture. Canadian Agricultural Economics and Farm Management Society, Occasional Paper No.1, 1990.

5. Harmonization and equivalence in organic agriculture, the Third Meeting, Rome 17-19.

6. J. D. House, The New Regional Development: Is Rural Development a Viable Option in Newfoundland and Labrador, Newfoundland Studies, vol. 17 (1): 11-31, 2001.

7. J. Dumanski, G. Coote, Lucerek and C. Lok, Soil Conservation in Canada, Journal of Soil and Water Conservation, Vol. 41, 1986.

8. J. S. Donald, Rural Redevelopment in Canada: The Case of Northeast New Brunswick. Journal of Rural Studies, vol.5 (2): 185-197, 1992.

9. J. Stabler, M. Olfert, and M. Fulton, The Changing Role of Rural Communities in an Urbanizing World, University of Regina, 1992.

10. K. Hamilton, Resource Accounting: Issues and Problems Related to Agriculture, Canadian Journal of Agricultural Economics, vol. 39 (4), Part 1, 1991.

11. M. Moraka, Decentralisation and participation for sustainable rural Development, University of Pretoria South Africa, 2000.

12. Ministry of Agriculture, Animal Industries and Fisheries, Programme for Targeting Commercial Agriculture Production in Uganda, Ref. No. 104. Uga. 26/110 (31), 1998.

13. Ministry of Agriculture, Animal Industry and Fisheries operationalisation of the rural development strategy for increased agricultural productivity, Uganda, 2005.

14. P. Santacoloma, Organic Certification Schemes: managerial skills and associated costs. Synthesis report from case studies in the rice and vegetable sectors. AGSF Occasional paper, 16, 2007.

15. R. C. Crook, and J. Manor, Democracy and Decentralization in South Asia and West Africa: Participation, Accountability and Performance, Cambridge: Cambridge University Press, 1998.

16. R. Gray, Economic Measures of Sustainability, Canadian Journal of Agricultural Economics, vol. 39 (4), 1991. 